\title{
Berguru Islam ke Barat dan Pengembangan Perguruan Tinggi Keagamaan Islam di Indonesia
}

\section{Studying Islam to the West and Developing Islamic Religious Colleges in Indonesia}

\author{
Abdul Zebar 1), Muhammad Irsan Barus 2) Candra Wijaya ${ }^{3)}$ \\ 1) Badan Akreditasi Nasional Pendidikan Anak Usia Dini dan Pendidikan Non formal Sumatera \\ Utara, Indonesia. \\ 2) Program Studi Pendidikan Agama Islam, Jurusan Tarbiyah dan Ilmu Keguruan, Sekolah \\ Tinggi Agama Islam Negeri Mandailing Natal \\ 3) Manajemen Pendidikan Islam, Fakultas Tarbiyah dan Ilmu Keguruan, Universitas Islam \\ Negeri Sumatera Utara \\ Diterima: Februari 2019; Disetujui: April 2019; Dipublish: Juni 2019.
}

\begin{abstract}
Abstrak
Tulisan ini mendeskripsikan latar belakang pengiriman dosen-dosen Perguruan Tinggi Keagamaan Islam (PTKI)) berguru Islam ke Barat dan kontribusi mereka terhadap pengembangan Perguruan Tinggi Keagamaan Islam (PTKI) di Indonesia. Secara historis yang melatarbelakangi pengiriman dosen Perguruan Tinggi Keagamaan Islam (PTKI) ke Barat adalah untuk mengubah studi Islam di Indonesia menjadi lebih komprehensif dengan metodologi dan tradisi keilmuan yang lebih universal. Proyek pengiriman tersebut ditentang oleh sebagian tokoh Islam karena dianggap akan melahirkan liberalisme dalam beragama. Di sisi lain pengiriman dosen tersebut didukung oleh sebagian tokoh Islam untuk menghilangkan kecendrungan sektarisme mazhab di Indonesia dan upaya integrasi keilmuan dalam Islam. Kontribusi alumni dosen Perguruan Tinggi Keagamaan Islam (PTKI) Barat antara lain (1) mendorong masuknya mata kuliah sains di Perguruan Tinggi Keagamaan Islam (PTKI); (2) rasionalisasi struktur organisasi kampus, (3) memperbaharui kurikulum dengan studi Islam lebih intensif dengan berbagai metodologi yang kaya; (4) penerbitan jurnal ilmiah; (5) membuka program pasca sarjana; dan (6) mengubah kajian di Perguruan Tinggi Islam dari bercorak mazhab ke pendekatan non-mazhabi.
\end{abstract}

Kata Kunci: Islam, Barat, Pengembangan, Perguruan Tinggi Keagamaan Islam

\begin{abstract}
This paper describes the background of sending lecturers of Islamic Religious Education (PTKI) to the Islamic West and their contribution to the development of ICM in Indonesia. Historically the background of sending Perguruan Tinggi Keagamaan Islam (PTKI) lecturers to the West was to change Islamic studies in Indonesia to become more comprehensive with more universal scientific methodologies and traditions. The shipping project was opposed by some Islamic leaders because it was considered to give birth to religious liberalism. On the other hand, the sending of lecturers was supported by a number of Islamic leaders to eliminate the tendency of sect sect of schools in Indonesia and efforts to integrate science in Islam. The contributions of alumni of Western Perguruan Tinggi Keagamaan Islam (PTKI) lecturers include (1) encouraging the entry of science courses in Perguruan Tinggi Keagamaan Islam (PTKI); (2) rationalizing the organizational structure of the campus, (3) updating the curriculum with more intensive Islamic studies with a variety of rich methodologies; (4) publishing scientific journals; (5) open post graduate programs; and (6) changing studies at Islamic Higher Education from the pattern of schools to the non-Mazhabi approach. Keywords: Islam, West, Development, Islamic Religious College
\end{abstract}

How to Cite: Zebar, A. Barus, M.I \& Wijaya, C. (2019). Berguru Islam ke Barat dan Pengembangan Perguruan Tinggi Keagamaan Islam di Indonesia. JUPIIS: Jurnal Pendidikan Ilmu-ilmu Sosial, 11 (2): 105112 .

${ }^{*}$ Corresponding author: ISSN 2085-482X (Print)

E-mail: (rabezludba@gmail.com) ISSN 2407-7429 (Online) 


\section{PENDAHULUAN}

Berdirinya

Perguruan Tinggi

Keagamaan Islam diawali dari keinginan para tokoh Islam untuk memajukan pendidikan Islam di Indonesia. Secara historis pendidikan Islam di Indonesia dipengaruhi oleh berbagai ragam pemikiran. Pada tahap awal di Perguruan Tinggi Keagamaan Islam (PTKI) paling tidak terdapat tiga ciri model pendidikan. Pertama, model pendidikan Timur Tengah, khususnya Universitas Al-Azhar yang juga diadopsi dalam mendirikan fakultasfakultas di Institut Agama Islam Negeri (IAIN) seperti fakultas Ushuluddin, Syariah dan Adab. Bahkan sistem ujian pun diambil dari Al-Azhar. Salah satu faktor penyebabnya adalah pengaruh model AlAzhar karena banyaknya lulusan Al-Azhar yang memegang peranan penting di Kementerian Agama ketika itu dan mereka turut berperan serta dalam merancang pendirian Perguruan Tinggi Keagamaan Islam (PTKI).

Kedua, model pendidikan lokal. Hal ini tergambar dari keinginan dari umat Islam Indonesia untuk memenuhi kebutuhan pembina dan guru agama. Atas dasar itulah dibuka fakultas Ushuluddin dan dakwah yang bertujuan untuk melahirkan pendakwah-pendakwah Islam di masyarakat. Ketiga, model pendidikan Barat. Model ini mengadopsi sistem kredit yang harus ditempuh oleh mahasiswa dalam periode tertentu (Huda, 2017).

Selain model pendidikan, ternyata pengaruh Barat terhadap pembaharuan Perguruan Tinggi Keagamaan Islam (PTKI) juga sangat Beragam. Ide-ide pembaharuan muncul sejak abad ke-19 sampai abad ke-20 di dunia Islam setelah adanya interaksi Islam dengan Barat di Mesir. Indonesia sebagai negara berpenduduk Islam juga mendapatkan dampak yang luar biasa dari ide-ide pembaharuan tersebut (Noer, 1980). Mulailah muncul ide-ide tentang integrasi ilmu yang menemukan momentumnya pada konferensi Islam tentang pendidikan sedunia di Mekkah pada tahun 1977 (Asari, 2015).

Ide pembaharuan juga semakin kencang berhembus di Perguruan Tinggi Keagamaan Islam (PTKI) sekembalinya para alumni yang disekolahkan oleh Kementerian Agama di luar negeri. Tulisan ini bertujuan untuk mendeskripsikan bagaimana proses dosen-dosen Perguruan Tinggi Keagamaan Islam (PTKI) berguru Islam ke Barat dan kontribusinya terhadap Pengembangan Perguruan Tinggi Islam di Indonesia.

\section{HASIL DAN PEMBAHASAN \\ Latar Belakang Gagasan dan Proyek Pengiriman}

Perguruan Tinggi Keagamaan Islam didirikan dengan maksud untuk melahirkan intelektual yang memiliki basis pengetahuan keislaman dan kebudayaan yang kuat. Ada beberapa gagasan yang melatarbelakangi pendirian Perguruan Tinggi Keagamaan Islam (PTKI), yaitu: Pertama, kesadaran umat Islam bahwa mereka tertinggal dalam bidang pendidikan; Kedua, masyarakat nonmuslim maju karena mengadopsi cara Barat dalam sistem pendidikan mereka; Ketiga, perlunya menghubungkan sistem pendidikan Islam dengan dunia internasional; Keempat, unsur lokal penting diperhatikan dalam pendidikan Islam (Fanani, 2007).

Pada perkembangannya, studi Islam di Perguruan Tinggi Keagamaan Islam (PTKI) tidak bisa dipisahkan dari kerangka studi Islam di berbagai belahan dunia Islam, khususnya di Mesir dan Arab Saudi. Studi ketika itu masih fokus pada ilmuilmu tradisional Islam, yaitu fiqh, ushul fiqh, hadis, ilmu hadis, tafsir, ilmu tafsir, ilmu kalam, dan bahasa Arab. Oleh karena itu, menurut Azyumardi Azra (1999) pada dasawarsa awal perkembangan Perguruan Tinggi Keagamaan Islam (PTKI) kajiankajian Islam memiliki tiga kecendrungan pokok: 1) Bersifat normatif -idealistik: Orientasi pada sektarianisme mazhab, 
khususnya mazhab Syafi'i dan kalam Asy'ari; 2) Kiblat keilmuan ke Timur Tengah: Terpencil dari wacana keilmuan yang luas

Selain itu, menurut M. Atho" Mudzhar (2002) ada 3 jenis metodologi konvensional yang berkembang di Institut Agama Islam Negeri (IAIN) sebelum tahun 1970-an. Pertama, metodologi penelitian tafsir yang terkait dengan topik-topik yang sekarang terangkum dalam ulumul Qur'an. Kedua, metodologi penelitian hadis yang terangkum dalam ilmu musthalah al-hadis. Ketiga, ilmu ushul fiqh atau ilmu dasardasar fiqh.

Ketiga metodologi ini membuat pengembangan keilmuan ketika itu belum begitu berkembang karena hanya hanya mengandalkan paradigma bayani, yaitu sebuah studi Islam yang berbasis teks dengan proses berpikir deduktif-analogis. Keadaan ini membuat proses pendidikan di Perguruan Tinggi Keagamaan Islam (PTKI) hanya meneruskan kegiatan pendalaman keilmuan yang ada di pesantren. Akhirnya membuat alumni Institut Agama Islam Negeri (IAIN) tidak begitu diperhitungkan di masyarakat. Melihat kondisi tersebut terbersit adanya keinginan untuk mengembangkan pendidikan Islam yang universal.

Ditambahlah lagi Perkembanganperkembangan yang terjadi dalam masyarakat Indonesia pada dasawarsa tahun 1970-an, yaitu: Pertama, masuknya modernisasi dari Barat yang berasumsi perlunya pembaharuan di negara-negara berkembang. Hal ini pun didukung oleh pemerintah orde baru dengan membentuk koalisi militer dan teknokrat hasil didikan Barat. Kedua, diadopsinya strategi pembangunan yang berpijak pada dua kaki, yaitu pembangunan pertanian untuk mencapai swasembada pangan yang berguna untuk menjaga stabilitas ekonomi-politik dan pada kaki yang lain yang berkaitan dengan industrialisasi sebagai upaya untuk memenuhi kebutuhan masyarakat secara massal melalui industri dalam negeri, ataupun melalui proses ekspor impor (Rahardjo, 1996).

Di sisi lain adanya muncul gerakan pembaharuan Nurcholish Madjid, dkk, tampilnya Mukti Ali sebagai Menteri Agama dan Harun Nasution sebagai Rektor Institut Agama Islam Negeri (IAIN) Jakarta yang mendorong terjadinya perubahan dalam kajian-kajian Islam (Azra, 1999). Perkembangan kajian-kajian Islam di Perguruan Tinggi Keagamaan Islam (PTKI) yang masa sebelumnya orientasi keilmuan cendrung ke Timur Tengah, khususnya Universitas Al-Azhar berkembang ke spektrum yang lebih luas. Dalam konteks inilah menurut Azyurmardi Azra, (1999) model pendekatan Barat terhadap Islam mulai muncul. Pendekatan ini menemukan momentum yang sangat luar biasa dengan kembalinya sejumlah tamatan Universitas Barat untuk mengajar di Institut Agama Islam Negeri (IAIN).

Fuad Jabali dan Jamhari mengklasifikasikan ada tiga generasi mahasiswa yang dikirim ke McGill University, yaitu generasi 1950, 1970, dan 1990. Generasi pertama 1950 antara lain diwakili oleh A. Mukti Ali, H. M. Rasjidi, Anton Timur Jaelani, Tedjaningsih Kaylani, Mochtar Naim, Harun Nasution, dan Kafrawi Ridwan. Harun Nasution adalah satu-satunya peraih gelar Ph.D. Generasi kedua antara lain A. Hafizh Basuki, Zaini Muchtarom, Murni Djamal, Muhammad Idris, Nouruzzaman Shiddiqy, Bisri Affandi, Saifuddin Ansyari, A. Farichin Chumaidy, dan Muhammad Asy"ari. Setelah vakum beberapa saat, proyek tersebut berlanjut kembali pada masa Menteri Agama Munawwir Syadzali (Fanani, 2007 Jurnal Ulumul Quran).

Selain itu menurut M. Atho Mudzhar dalam bukunya 'Belajar Islam di Amerika' yang dikutip oleh Najmu Hayati (Proseding Gerakan Islam, 2010), ada beberapa hal yang mendorong para dosen Perguruan Tinggi Keagamaan Islam (PTKI) belajar Islam ke Barat, yaitu: 1) Bahwa para dosen yang dikirim ke Barat bukan belajar Islam 
dari orang Barat tetapi mempelajari Islam menurut pandangan Barat walaupun diakui bahwa memang ada sentimen orientalis terhadap Islam, tetapi tidak semua orientalis memiliki pemikiran yang seperti itu; 2) Orang Barat mempunyai tradisi keilmuan yang lebih baik dari kebanyakan orang Islam. Barat sangat menghargai naskah-naskah lama, koleksi perpustakaan yang lengkat dan sikap kritis yang tinggi; 3) Buku yang dibaca bukan selamanya buku karangan orientalis, malah sebagian besar buku yang dibaca adalah buku berbahasa Arab dan berbahasa Inggris yang ditulis oleh orang Islam; 4) Ada beasiswa dari pemerintah yang memberikan kesempatan untuk belajar Islam di Amerika.

Perkenalan dengan studi Islam di Barat secara sistematis diawali oleh A. Mukti Ali yang dikenal sebagai pelopor perubahan kiblat Perguruan Tinggi Keagamaan Islam (PTKI) dari Timur Tengah ke Barat. Sejak saat itu banyak dosen-dosen Perguruan Tinggi Keagamaan Islam (PTKI) yang kuliah ke Barat untuk mempelajari Islam dari kacamata Barat di berbagai universitas Eropa dan Amerika. Ketika menjabat Menteri Agama tahun 1971-1978, Mukti Ali banyak mengirimkan dosen PTAI (Institut Agama Islam Negeri (IAIN)) ke negara-negara Barat. Hal itu dapat dipahami karena Ali sendiri mendapatkan gelar MA dari McGill University di Kanada. Perkenalan dengan studi Islam di Barat membuat studi Islam di Perguruan Tinggi Keagamaan Islam (PTKI) mengalami perkembangan pesat, terutama dari sudut metodologi dan pendekatannya. Studi Islam tidak lagi terbatas kepada ilmu-ilmu tradisional Islam dengan metodologi konvensional, melainkan menjadi luas dengan penggunaan disiplin ilmu sosial dan humaniora. Persentuhan antara Perguruan Tinggi Keagamaan Islam (PTKI) dengan lembaga-lembaga pendidikan Barat membuka pintu bagi pengkajian Islam yang lebih bersifat metodologis dan historis.

Pada umumnya kajian tentang Islam diajarkan oleh tokoh-tokoh Orientalis yang ahli di bidang ilmu ketimuran atau bahkan ahli tentang agama Islam secara mendalam, walaupun secara realitas mereka tidak memeluk agama Islam. Para alumni universitas Barat yang mengambil Studi Pengkajian Islam (Islamic Studies) tersebut kemudian kembali ke tanah air dengan mengembangkan ilmu yang diperolehnya dan diajarkan di berbagai universitas atau institut yang ada di Indonesia. Pada umumnya kajian Islam (Islamic Studies/Dirasah Islamiyah) lebih banyak dilakukan di Institut Agama Islam Negeri (IAIN) karena sebagian dosendosennya adalah alumni dari Universitas di Barat, seperti Universitas Mc Gill Kanada, Universitas Sorbone Perancis, Universitas Leiden Belanda, Universitas California Amerika Serikat, Universitas Chicago Amerika Serikat dan sebagainya.

\section{Argumentasi Pro-kontra terhadap Pengiriman Dosen}

Pengiriman dosen-dosen untuk belajar ke Barat mengalami pro dan kontra. Para tokoh yang pro beranggapan bahwa selama ini pengembangan keilmuan di Perguruan Tinggi Keagamaan Islam (PTKI) cendrung sektarisme mazhab tertentu. Alur pikiran yang dibangun oleh pihak yang pro adalah perlunya memperluas cakupan pengembangan keilmuan yang awalnya terbatas. Secara kelembagaan pada awalnya bentuk sekolah tinggi dengan nama PTAIN (Perguruan Tinggi Islam Negeri) yang kemudian dikembangkan menjadi institut dengan nama Institut Agama Islam Negeri (IAIN). Cakupan ilmu lebih luas di Institut Agama Islam Negeri (IAIN) daripada PTAIN. Seterusnya, perkembangan pemikiran tentang gagasan integrasi ilmu antara ilmu-ilmu kewahyuan dan nonkewahyuan (perennial knowledge dan acquired knowledge) melahirkan 
Universitas Islam Negeri (Daulay \& Ja'far, 2016). Keinginan untuk berubah inilah yang menjadi landasan berpikir untuk mengirimkan dosen-dosen Perguruan Tinggi Keagamaan Islam (PTKI) belajar ke Barat agar cakupan keilmuan mereka lebih universal.

Kemajuan ilmu pengetahuan dan teknologi yang progresif dipandang bukan merupakan sumbangan perguruan tinggi Islam, melainkan produk karya perguruan tinggi yang tidak membawa-bawa level Islam. Perguruan tinggi Islam, khususnya di Indonesia masih sibuk mengurus pengembangan ilmu-ilmu keagamaan an sich, seperti ushuluddin, ilmu syariah, ilmu tarbiyah, ilmu adab dan ilmu dakwah yang membuat Islam dipandang sebagai agama yang sempit. Sementara metodologi yang digunakan pun masih terbatas. Oleh karena itulah metodologi dan ragam perspektif untuk mengkaji Islam secara komprehensif. Makanya perlu diutus dosen-dosen untuk belajar ke negaranegara yang mengkaji Islam untuk mendapatkan pemahaman yang lebih universal.

Selain itu, dalam tradisi intelektual Islam di masa lampau bahwa Islam tidak mengenal dikotomi ilmu. Ilmu itu ibarat hikmah yang bisa diambil dari mana saja. Hal ini baru disadari oleh umat Islam sejak munculnya pembaharuan pemikiran Islam di Timur Tengah seperti yang digagas oleh Muhammad Ali Pasha, al-Tahtawi, Jamal Al-Din al-Afghani dan Muhammad Abduh (Asari, 2007). Pembaharuan di Mesir berpengaruh bagi pelajar-pelajar Islam Indonesia untuk juga mendalami bagaimana proses pembelajaran di Barat. Ide dan pemikiran untuk mendirikan perguruan tinggi di kalangan umat Islam yang telah muncul pada tahun 1930-an baru bisa dikembangkan menjadi Institut Agama Islam Negeri (IAIN) pada tahun 1960 dan baru muncul UIN pada tahun 2000-an.

Pengiriman para dosen ke negaranegara Barat menjadi pilihan bagi perubahan kebijakan di PTAI (Institut Agama Islam Negeri (IAIN)) dalam jangka panjang. Sebagian besar dari nama-nama di atas menduduki peran penting dalam perkembangan orientasi studi Islam di lingkungan Institut Agama Islam Negeri (IAIN). Tidak mengherankan apabila pada masa-masa selanjutnya, pengaruh studi Islam di Barat sangat terasa, khususnya di program magister maupun program doktor. Secara kelembagaan Harun Nasution adalah pelopor kajian Islam dengan menggunakan metodologi Barat di Institut Agama Islam Negeri (IAIN).

Kelompok yang kontra meranggapan bahwa belajar Islam ke Barat akan menimbulkan dampak yang tidak baik. Ini terlihat dari nada sumbang tentang pendekatan model Barat yang dicurigai sebagai menerapkan pendekatan orientalis dalam mengkaji Islam (Azra, 1999).

Selain itu, kritik pengiriman para dosen Institut Agama Islam Negeri (IAIN) ke luar negeri, khususnya ke perguruanperguruan tinggi di Barat, dianggap sebagai salah satu biang keladi menjamurnya gagasan-gagasan menyimpang yang bermunculan di Perguruan Tinggi Keagamaan Islam (PTKI). Hartono Ahmad Jaiz bahkan secara terang-terangan beranggapan bahwa pengiriman mahasiswa/dosen ke Barat ikut bertanggung jawab terhadap proses pemurtadan di beberapa Institut Agama Islam Negeri (IAIN) (Jaiz, 2006).

Pengaruh ini menurut kaum fundamentalis melahirkan umat Islam yang dikategorikan "liberal." Dalam konteks tersebut, Institut Agama Islam Negeri (IAIN) menjadi tempat berkembangnya liberalisme dalam beragama. Hal itu sebagai konsekuensi Perguruan Tinggi Keagamaan Islam (PTKI) yang menempatkan agama sebagai objek ilmu sehingga hal-hal yang sakral mengalami proses desakralisasi. Itulah konsekuensi logis upaya memajukan PTAI sebagai lembaga keilmuan dan intelektual. Kaum liberal mendapatkan habitat yang 
tepat di PTAI. Para pengambil kebijakan di Institut Agama Islam Negeri (IAIN) pun tampaknya tidak menolak kecenderungan kajian-kajian Islam yang menggunakan pendekatan-pendekatan baru tersebut dan lebih melihat itu sebagai dinamika dan proses pendewasaan pemikiran (Husaini, 2006).

\section{Kontribusi Alumni Barat dalam Kemajuan perguruan tinggi keagamaan islam (PTKI)}

Gagasan pendirian sekolah tinggi Islam yang awalnya diprakarsai oleh beberapa tokoh nasional yang berlatar belakang pendidikan Barat seperti $M$. Natsir, Satiman dan Muhammad. Gagasan mereka dilatarbelakangi pemikiran pragmatis-objektif kondisi pendidikan Islam yang masih jauh tertinggal pengembangan pendidikannya dibandingkan dengan pendidikan nonmuslim (Suprayogo \& Rasmianto, 2006). Mereka berpendapat perlunya menghubungkan sistem pendidikan Islam dengan dunia internasional agar memasukkan masyarakat Islam ke dalam kelompok terdidik.

Selain itu, gagasan dari alumni Barat (modernis) dalam mengembangkan Perguruan Tinggi Keagamaan Islam (PTKI) berbeda dengan kaum tradisional. Ada beberapa perbedaan perhatian dari kaum tradisionalis dan modernis (Alumi Barat) dalam mengembangkan Perguruan Tinggi Keagamaan Islam (PTKI). Kaum tradisionalis cenderung menekankan penambahan jumlah Perguruan Tinggi Keagamaan Islam (PTKI), fakultas-fakultas, termasuk fakultas cabang maupun kelas jauh, bahkan kelas-kelas jauh yang berada di kota-kota propinsi lain maupun kota kabupaten. Kecenderungan kedua dari kaum tradisionalis adalah upaya mempertahankan studi Islam dalam bentuknya yang mirip dengan kurikulum pesantren atau universitas Al-Azhar, dalam arti banyak menekuni kitab-kitab berbahasa Arab dan kurang menerima ilmu pengetahuan umum sebagai ilmu bantu.

Sementara itu kecenderungan alumni Barat adalah justru sebaliknya. Mereka mendorong dimasukkannya mata kuliahmata kuliah umum yang kebanyakan menggunakan buku-buku berbahasa Indonesia ke dalam kurikulum Institut Agama Islam Negeri (IAIN). Buku-buku berbahasa Indonesia ini semula dimaksudkan hanya untuk ilmu-ilmu bantu, tetapi kemudian ternyata juga menjalar kepada ilmu-ilmu inti, sehingga secara perlahan ikut menurunkan mutu Institut Agama Islam Negeri (IAIN) karena semakin lemahnya para alumni dalam penguasaan bahasa Arab. Kecenderungan kedua dari kaum alumni Barat ialah obsesinya terhadap rasionalisasi organisasi Institut Agama Islam Negeri (IAIN). Kelas-kelas jauh Institut Agama Islam Negeri (IAIN) dihapuskan atau digabungkan dengan yang lain, jumlah fakultas diupayakan tidak bertambah lagi, atau bahkan kalau dapat dikurangi. Jumlah mahasiswa juga dikendalikan. Puncak dari kegiatan rasionalisasi organisasi ini, ialah dilepasnya sekitar 40 fakultas cabang Institut Agama Islam Negeri (IAIN)menjadi 36 Sekolah Tinggi Agama Islam Negeri (STAIN) yang berdiri sendiri pada 1997, di luar 14 Institut Agama Islam Negeri (IAIN) yang ada.

Tidak dapat dipungkiri bahwa pergantian Menteri Agama dari dominasi NU ke Prof. Mukti Ali memberikan beberapa perubahan. Mukti Ali kembali ke Indonesia, kemudian beraktivitas di Institut Agama Islam Negeri (IAIN) Sunan Kalijaga Yogyakarta, sementara Harun Nasution di Institut Agama Islam Negeri (IAIN) Syarif Hidayatullah Jakarta. Dari tangan mereka inilah reformasi dan reorientasi kajian Islam di Institut Agama Islam Negeri (IAIN) mulai. Mukti Ali memperkenalkan mata kuliah perbandingan agama yang menjadi titik awal pengenalan kajian Islam lebih kritis. Harun Nasution lebih-lebih 
mengintrodusir kajian Islam yang kontroversial seperti filsafat, kalam/teologi, tasawuf, dan pemikiran modern dalam Islam. Bukan sebab mata kuliahnya, tetapi pendekatan rasional dan kritis terhadap Islam yang menjadi titik picu perdebatan di internal Institut Agama Islam Negeri (IAIN). Secara garis besar Kontribusi alumni Barat untuk memodernisasi pendidikan Islam antara lain: 1) Mendorong masuknya mata kuliahmata kuliah 'umum' dan sains yang kebanyakan berbahasa non-Arab ke dalam kurikulum Institut Agama Islam Negeri (IAIN); 2) Rasionalisasi organisasi Institut Agama Islam Negeri (IAIN). Kelas-kelas jauh dihapuskan atau dimerger dengan yang lain. Jumlah fakultas diupayakan tidak bertambah, atau bahkan kalau dapat dikurangi. Jumlah mahasiswa juga dikendalikan. Puncaknya dari kegiatan rasionalisasi tersebut adalah dilepasnya sekitar 40 fakultas cabang Institut Agama Islam Negeri (IAIN) pada tahun 1997. 3) Menyerukan diajarkannya ilmu pengetahuan dan teknologi di samping mengajarkan ilmu keislaman murni (Huda, 2017).

4) Mendorong studi Islam lebih intensif dengan berbagai metodologi yang kaya. Contoh studi Sejarah Islam dan fiqh Islam. Di banyak negara Islam termasuk di Indonesia, dalam mengkaji sejarah Islam yang dijadikan referensi primer adalah para penulis kontemporer sedangkan di Barat yang menjadi referensi primer adalah buku-buku kuno yang ditulis langsung dari pelaku sejarah atau penulis yang lebih dekat hidupnya dari peristiwa itu. Kemudian, dalam mengkaji Islam di banyak negara Islam menggunakan referensi ulama klasik, sementara di Barat menggunakan referensi ulama kontemporer (Proceding Gerakan Islam, 2010).

5) Menumbuhkan tradisi ilmiah yang semua bercorak hapalan dan cendrung menganut mazhab tertentu menjadi sistem perkuliahan yang mengajak mahasiswa berpikir kritis, inovatif, objektif dan menghargai perbedaan;

Memperbaharui kurikulum yang semula hanya memuat bidang kajian agama dan aliran mazhab tertentu dengan berbagai mata kuliah non keagamaan seperti filsafat, sosiologi, antropologi dan lain sebagainya; 7) Penerbitan jurnal ilmiah sebagai wadah dosen untuk mengasah bakat keilmuan; 8) Membuka program pasca sarjana yang dimulai pada tahun 1982 untuk program pascasarjana untuk strata 2 (s-2) da strata 3 (s-3) yang merupakan kelanjutan dari program purna sarjana (Nata, 2005).

Mengubah kajian di Perguruan Tinggi Islam dari bercorak mazhab ke pendekatan non-mazhabi. Jika sebelumnya kajian keislaman cendrung memihak pada mazhab tertentu, maka setelah masuknya alumni Barat, kecendrungan untuk mengkaji tentang Islam cendrung lebih kepada eksposisi "ilmiah" tentang berbagai mazhab dan aliran yang tumbuh dan berkembang dalam Islam; tanpa ada unsur keharusan memilih dan menghakimi mazhab tertentu. Hasil pendekatan ini menjadikan pemahaman sektarianisme di masyarakat memudar. Hal ini berkat banyaknya lulusan Perguruan Tinggi Keagamaan Islam (PTKI) yang terjun langsung ke masyarakat dan memberikan penjelasan yang proporsional. Hasilnya, pertikaian furu'iyah yang dahulunya kerap terjadi relatif semakin berkurang. Dengan begitu toleransi perbedaan mazhab dan aliran pemikiran semakin berkembang.

Kajian Islam Islam yang awalnya bersifat normative menjadi bersifat historis, sosiologis dan empiris. Pendekatan normatif menghasilkan pandangan yang serba idealistik terhadap ajaran Islam; yang membuat kaum muslimin terjebak dalam "kepuasan batin" semu. Sebaliknya, pendekatan historis sosiologis membuka mata mahasiswa Perguruan Tinggi Keagamaan Islam (PTKI) tentang realitas yang dihadapi Islam dan 
kaum muslimin sepanjang sejarah. (Azra, 1999).

\section{SIMPULAN}

Berdasarkan pembahasan di atas dapat disimpulkan bahwa latar belakang pengiriman dosen Perguruan Tinggi Keagamaan Islam (PTKI) ke Barat untuk belajar Islam adalah adanya keinginan untuk memperbaiki kualitas studi Islam di Indonesia yang jauh tertinggal dibandingkan Barat. Di sisi lain ada upaya untuk menghubungkan kajian Islam di Indonesia dengan dunia internasional yang lebih luas. Pengiriman itu bagi sebagian kalangan dianggap menjadi salah satu penyebab tumbuhnya upaya liberalisasi agama. Namun di sisi lain pengiriman itu dianggap sebagai upaya untuk mewujudkan konsep integrasi keilmuan dalam Islam yang sejak awal tidak mengenal dikotomi dan upaya untuk menghilangkan sektarisme mazhab tertentu di kalangan umat Islam Indonesia. Selain itu, ada beberapa kontribusi alumni Barat bagi pengembangan Perguruan Tinggi Keagamaan Islam (PTKI), di antaranya: (a) mendorong masuknya mata kuliah-mata kuliah 'umum' dan sains yang kebanyakan berbahasa non-Arab ke dalam kurikulum Institut Agama Islam Negeri (IAIN); (b) Rasionalisasi organisasi dan mendorong studi Islam lebih intensif dengan berbagai metodologi yang kaya; (c) memperbaharui kurikulum yang semula hanya memuat bidang kajian agama dan aliran mazhab tertentu dengan berbagai mata kuliah non keagamaan seperti filsafat, sosiologi, antropologi dan lain sebagainya; (d) penerbitan jurnal ilmiah dan membuka program pasca sarjana dan (e) mengubah kajian di Perguruan Tinggi
Keagamaan Islam (PTKI) dari bercorak mazhab ke pendekatan non-mazhabi. Kajian Islam yang awalnya bersifat normatif menjadi bersifat historis, sosiologis dan empiris.

\section{DAFTAR PUSTAKA}

Asari, H. (2015). (Editor). Universitas Islam Negeri Sumatera Utara; Memperkokoh Eksistensi Memperluas Kontribusi. Medan; IAIN Press.

Asari, H.. (2007). Modernisasi Islam; Tokoh, Gagasan dan Gerakan. Bandung: Citapusta Media.

Daulay, A \& Ja'far. (2016). Falsafah Pendidikan Islami; Menguak Nilai-Nilai Pendidikan dalam Tradisi Islam. Medan: Perdana Publising.

Azra, A. (1999). Pendidikan Islam; Tradisi dan Modernisasi Menuju Milenium Baru. Jakarta: LOGOS Wacana Ilmu.

Huda, N. (2017). Islam Nusantara: Sejarah Sosial Intelektual Islam di Indonesia. Yogyakarta: Ar-Ruzz Media.

Husaini, A. (2006). Hegemoni Kristen-Barat dalam Studi Islam di Perguruan Tinggi. Jakarta: Gema Insani.

Proseding Gerakan Islam Merespon Isu Kontemporer. 2010. IAIN Imam Bonjol Padang.

Mudzhar, M. A. (2002). Pendekatan Studi Islam dalam Teori dan Praktek. Yogyakarta: Pustaka Pelajar, 2002.

Nata, A. (2005). Tokoh-Tokoh Pembaruan Pendidikan Islam di Indonesia. Jakarta: RajaGrafindo Persada.

Noer, D. (1980). Gerakan Modern Islam di Indonesia 1900-1942. Jakarta: Pustaka LP3ES.

Rahardjo, M. D. (1996). Intelektual Intelegensia dan Perilaku Politik Bangsa. Bandung: Mizan.

Suprayogo, I \& Rasmianto. (2008). Perubahan Pendidikan Tinggi Islam; Refleksi Perubahan IAIN/STAIN Menjadi UIN. Malang: UINMalang Press.

Ulumuna; Jurnal Studi Keislaman Volume XI Nomor 1 Juni 2007. 